\title{
KEANEKARAGAMAN REPTIL DI REPONG DAMAR PEKON PAHMUNGAN PESISIR BARAT (STUDI KASUS PLOT PERMANEN UNIVERSITAS LAMPUNG)
}

\section{(THE BIODIVERSITY OF REPTILE IN REPONG DAMAR PAHMUNGAN VILLAGE WEST COAST (UNIVERSITY OF LAMPUNG PERMANENT PLOT CASE OF STUDY))}

\author{
Ari Winata Findua ${ }^{1)}$, Sugeng P. Harianto ${ }^{1)}$, dan Nuning Nurcahyani ${ }^{2)}$ \\ 1) Jurusan Kehutanan Fakultas Pertanian Universitas Lampung \\ 2) Jurusan Biologi Fakultas Matematika dan Pengetahuan Alam Universitas Lampung \\ Jl. Soemantri Brojonegoro No. I Bandar Lampung \\ E-mail : ariwinataxxx@yahoo.co.id \\ No.Telpon : 085768680945
}

\begin{abstract}
ABSTRAK
Repong Damar di Pekon Pahmungan kecamatan Krui, Kabupaten Pesisir Barat merupakan penyangga Taman Nasional Bukit Barisan Selatan (TNBBS), sehingga memiliki peran penting terhadap kawasan konservasi tersebut. Reptil merupakan salah satu fauna yang terdapat di Pahmungan, penelitian ini menjadi penting dilakukan karena belum tersedianya data mengenai spesies reptil. Penelitian dilakukan pada bulan Juni 2015 yang bertujuan untuk mengetahui keanekaragaman reptil di Repong Damar Pekon Pahmungan Pesisir Barat (Studi Kasus Plot Permanen Universitas Lampung). Penelitian ini menggunakan metode Visual Encounter Survey (VES). Hasil penelitian keanekaragaman reptil ditemukan 15 spesies reptil dengan jumlah individu 323 yang berasal dari 7 famili dan diperoleh nilai indeks keanekaragaman $H^{\prime}=2,0008$ yang termasuk dalam kategori sedang dan indeks kesamarataan $J^{\prime}=0,927$ yang termasuk dalam kategori stabil. Spesies reptil yang sering dijumpai adalah kadal pari (Tachydromus sexlineatus), kadal kebun (Eutropis multifasciata), kadal pohon hijau (Dasia olivacea), kadal terbang (Draco obscurus), cicak terbang (Draco volans), tokek (Gecko gecko)dancicak kayu (Hemidactylus frenatus) $(\mathrm{n}=72,54,42,38,28,28,27)$.
\end{abstract}

Kata kunci: reptil, repong damar, visual encounter survey

\section{ABSTRACT}

Repong Damar in Pahmungan village, West Coast Regency is a Bukit Barisan Selatan National Park buffers, plays an important role a national preservation zone. Reptile is one of fauna in Pahmungan, the research had to be done because there wasn't available data abaut reptiles. The research was conducted on June 2015, the aim of this study was to know the Biodiversity of Reptile Species in Repong Damar, Pahmungan village West Coast (University of Lampung permanent plot case study), The method in this research was used Visual Encounter Survey (VES) method. The result showed, there are 15 reptile species from 7 families $(N=323)$ and biodiversity index $H^{\prime}=2,008$ which included as average category and Index of evennessJ'=0,927 which included as stable. Reptile species often encountered was Tachydromus sexlineatus, Eutropis multifasciata, Dasia olivacea, Draco obscurus, Draco volans, Gecko geckoand Hemidactylus frenatus $(\mathrm{n}=72,54,42,38,28$, 28,27).

Keywords: reptile, repong damar, visual encounter survey 


\section{PENDAHULUAN}

Indonesia merupakan salah satu negara yang memiliki keanekaragaman hayati paling tinggi di dunia. Menurut World Wildlife Fund Indonesia(2007), keanekaragaman hayati yang terkandung di hutan Indonesia meliputi $12 \%$ spesies mamalia dunia, 7,3\% spesies reptil dan amfibi, serta $17 \%$ spesies burung dari seluruh dunia. Reptilia merupakan sekelompok vertebrata yang menyesuaikan diri di tempat yang kering di tanah. Penandukan atau cornificatio kulit dan squama atau carpace untuk menjaga banyak hilangnya cairan dari tubuh pada tempat yang kasar (Jasin, 1984).

Repong Damar terdapat di Pekon Pahmungan, Kecamatan Pesisir Tengah, Kabupaten Pesisir Barat, Propinsi Lampung. Secara geografis letak pekon Pahmungan berada di tepi Taman Nasional Bukit Barisan Selatan (TNBBS), sehingga memiliki peran penting sebagai penyangga kawasan pelestarian alam tersebut. Keanekaragaman jenis satwa di Repong Damar terdiri dari 16 jenis Aves (Firdaus, Setiawan dan Rustiati 2014),mamalia, 4 Jenis primata (Nainggolan dan Dewi, 2011), reptilia dan amphibi. Setiap jenis mempunyai peluang yang sama dalam setiap perjumpaanya. Selain mengetahui kebiasaan hidupnya, penting juga memprediksikan jenis yang dijumpai berdasarkan makro habitatnya yaitu akuatik, teresterial, fossorial atau arboreal (Mistar, 2003; Amri, Nurdjali dan Siahaan, 2015).

Reptil merupakan salah satu fauna yang terdapat di wilayah Indonesia. Indonesia menempati peringkat ketiga sebagai negara yang memiliki kekayaan jenis reptil paling tinggi di dunia, lebih dari 600 jenis reptil terdapat di Indonesia (Bappenas, 1993), Pulau Sumatera memiliki 300 jenis reptil dan amfibi dan 23\% diantaranya merupakan jenis endemik. Reptilmerupakan sekelompok vertebrata yang menyesuaikan diri di tempat yang kering di tanah. Penandukan atau cornificatio kulit dan squama atau carpace untuk menjaga banyak hilangnya cairan dari tubuh pada tempat yang kasar (Jasin, 1984).

Tujuan dari penelitian ini adalah mendapatkan informasi mengenai keanekaragaman jenis dan sebaran ekologi reptil di Repong Damar Desa Pahmungan Kecamatan Pesisir Tengah Krui Kabupaten Pesisir Barat.

\section{METODE PENELITIAN}

Penelitian ini dilaksanakan pada bulan Juni 2015 di Repong Damar, Pekon Pahmungan, Kecamatan Pesisir Tengah, Kabupaten Pesisir Barat. Alat yang digunakan dalam penelitian ini adalah Global Positioning System(GPS), kamera digital, jam tangan digital, alat tulis, buku panduan lapang,tali rapia, laptop dan lembar data/kerja. Objek penelitian adalah reptilyang berada di areal plot permanen Universitas Lampung Repong Damar, Pekon Pahmungan. Data yang dikumpulkan yaitu data primer mengenai spesies-spesies reptil yang dijumpai di lokasi. Metode yang digunakan dalam penelitian ini adalah Visual Encounter Survey (VES) atau Survei Perjumpaan Visual (Heyer, Donnelly, McDiarmid, Hayek, dan Foster, 1994), yang dikombinasikan dengan metode Line Transek (transek sampling) (Kusrini, Endarwin, UI-Hasanah dan Yazid, 2007), dan data sekunder meliputi data penunjang yang berkaitan dengan penelitian ini untuk mencari, mengumpulkan, dan menganalisis data penunjang berupa keadaan fisik lokasi penelitian, iklim, vegetasi, jenis hewan yang merupakan predator, jenis pakan reptil serta jenis-jenis reptil menggunakan studi literatur. Observasi langsung yang dilakukan pada bulan Juni selama 12 hari efektif dimulai dari pukul 07.00-17.00 WIB. 


\section{HASIL DAN PEMBAHASAN}

\section{A. Keanekaragaman Spesies Reptil}

Berdasarkan hasil penelitian di Pekon Pahmungan Kabupaten Pesisir Barat (Plot Permanen Universitas Lampung), ditemukan 15 spesies reptil dengan total 323 individu yang berasal dari 7 famili disajikan pada Tabel 1.

Tabel 1. Spesies-spesies reptil yang terdapat di Pekon Pahmungan Kecamatan KruiKabupaten Pesisir Barat Juni 2015.

\begin{tabular}{llllc} 
No. & Famili & Nama Species & Nama Latin & Jumlah \\
\hline 1 & Colubridae & Ular koros & Ptyas korros & 1 \\
2 & Colubridae & Ular pucuk & Ahaetulla prasina & 2 \\
3 & Elapidae & Ular welang & Bungarus fasciatus & 1 \\
4 & Elapidae & Ular kepala merah & Bungarus flaviceps & 1 \\
5 & Elapidae & Ular weling & Bungarus candidus & 3 \\
6 & Natricidae & Ular kisik & Xenochrophis vittatus & 1 \\
7 & Scincidae & Kadal pohon hijau & Dasia olivacea & 42 \\
8 & Scincidae & Kadal ular & Lygosoma quadrupes & 24 \\
9 & Scincidae & Kadal kebun & Eutropis multifasciata & 54 \\
10 & Lacertidae & Kadal pari/rumput & Tachydromus sexlineatus & 72 \\
11 & Agamidae & Kadal terbang & Draco obscurus & 38 \\
12 & Agamidae & Cicak/kadalterbang & Draco volans & 28 \\
13 & Agamidae & Bunglon & Bronchocela jubata & 1 \\
14 & Gekkonidae & Cicak kayu & Hemidactylus frenatus & 27 \\
15 & Gekkonidae & Tokek & Gecko gecko & 28 \\
\hline
\end{tabular}

Ular koros (Ptyas korros)saat penelitianditemukan berada pada semak-semak, berwarna coklat muda dari ekor sampai kepala. Reptil ini dijumpai di plot 3 pada hari ke6dan hanya ditemukan 1 ekor selama penelitian. Ular koros bertubuh cukup besar, hingga 2 meter panjangnya. Sisi atas tubuh berwarna coklat muda kekuningan hingga abu-abu kehitaman. Ular pucuk (Ahaetulla prasina) selama penelitian reptil ini dijumpai di 2 waktu dan plot yang berbeda yaitu plot 6 pada hari ke-10 dan plot 1 pada hari ke-11 ditemukan berada pada dahan atau ranting yang sudah mati dengan jumlah 2 ekor selama penelitian. Menurut Tweedie (1983), ular ini berwarna hijau, panjang dan sangat ramping, panjang tubuh keseluruhan mencapai $2 \mathrm{~m}$, meski kebanyakan sekitar $1,5 \mathrm{~m}$ atau lebih lebih dari sepertiganya adalah ekornya yang kurus seperti cambuk, kepala panjang meruncing di moncong, jelas lebih besar daripada leher yang kurus bulat seperti ranting hijau, mata besar, kuning, dengan celah mata (pupil) mendatar.Ular welang (Bungarus fasciatus)saat penelitian ditemukan berada pada lantai hutan menjelang malam, berwarna hitam dan kuning. Reptil ini dijumpai di plot 10 pada hari ke-12reptil ini hanya ditemukan 1 ekor selama penelitian.Ular yang berukuran sedang, dengan panjang maksimum yang tercatat $2125 \mathrm{~mm}$, akan tetapi umumnya ular dewasa hanya sekitar 1,5 m atau kurang. Ular kepala merah (Bungarus flaviceps) ditemukan berada pada lantai hutan. Reptil ini dijumpai di plot 2 pada hari ke-8 reptil ini hanya ditemukan 1 ekor selama penelitian. Ular ini tergolong jenis Bungarus yang 
berukuran besar, dapat mencapai panjang total $1900 \mathrm{~mm}$. Bagian atas kepala, leher dan sebagian tengkuknya hingga ekor berwarna merah menyala. Ular welling (Bungarus candidus) saat penelitian ditemukan berada pada semak belukar. Reptil ini dijumpai di plot 10 pada hari ke-4, plot 10 hari ke-5, plot 3 hari ke-9, reptil ini ditemukan sebanyak 3 ekor. Panjang total tubuhnya dapat mencapai $1280 \mathrm{~mm}$. Kepala berwarna hitam dengan bagian bibir, dagu dan dagunya berwarna putih. Ular kisik reptil ini dijumpai di plot 3 pada hari ke10reptil ini hanya ditemukan 1 ekor selama penelitian.Ular kisik umumnya bertubuh kecil ramping. Panjang tubuh maksimal mencapai $70 \mathrm{~cm}$, namun umumnya hanya sekitar $50 \mathrm{~cm}$. Ekornya sekitar seperempat dari seluruh panjang tubuhnya. Kepala berwarna hitam di bagian atas, dengan coret-coret putih yang berpola simetris.

Kadal pohon hijau (Dasia olivacea selama penelitian ditemukan sering kali berada di balik seresah, batang pohon yang sudah mati, bebatuan, batang pohon. Reptil ini ditemukan setiap hari di semua plot dengan jumlah 42 ekor.Menurut Das (2010), ciri-cirinya adalah kadal yang bertubuh gempal, panjang tubuh dari moncong hingga anus maksimal $115 \mathrm{~mm}$, panjang total hingga ujung ekor mencapai $292 \mathrm{~mm}$.Kadal ular (Lygosoma quadrupes) selama penelitian ditemukan sering kali berada pada di balik seresah, batang pohon yang sudah mati, bebatuan, batang pohon. Reptil ini ditemukan di setiap harinya dan di semua plot dengan jumlah 24 ekor. Menurut Das (2010), kadal berukuran kecil dengan bentuk tubuh hampir silindris ini memiliki panjang keseluruhan hingga sekitar $192 \mathrm{~mm}$ dengan ekor kira-kira setengahnya atau kurang sedikit.Kadal Kebun (Eutropis multifasciata)selama penelitian ditemukan sering kali berada pada di balik seresah, batang pohon yang sudah mati, bebatuan. Reptil ini ditemukan setiap harinya dan di semua plot dengan jumlah 54 ekor. Menurut Das (2010) ciri-cirinya adalah punggung berwarna cokelat zaitun dengan jalur coklat gelap bertepi terang keputih-putihan atau kekuning kuningan di sisi badannya. Kadal pari/rumput (Tachydromus sexlineatus) selama penelitian ditemukan sering kali berada di balik seresah, batang pohon yang sudah mati, bebatuan, batang pohon. Reptil ini ditemukan setiap hari dan di semua plot dengan jumlah 72 ekor. Menurut Das (2010), ciri-cirinya adalah memiliki leher yang panjang dan moncong meruncing, serupa dengan biawak namun berukuran jauh lebih kecil dan kurus. Kadal terbang (Draco obscurus) sering kaliditemukan berada pada dahan, atau batang pohon, berwarna dominan abu-abu dengan corak hitam. Reptil ini ditemukan setiap hari dan di semua plot dengan jumlah 38 ekor. Menurut Das (2010), kadal ini memiliki tubuh yang ramping dan bergerak lincah, biasanya memakan spesies lain seperti semut dan rayap. Cicak/kadal terbang (Draco volans) selama penelitian ditemukan sering kali berada pada dahan, batang pohon, berwarna dominan abu-abu seperti batang pohon. Reptil ini ditemukan di setiap harinya dan di semua plot dengan jumlah 28 ekor. Menurut Das (2010) Kadal yang berukuran kecil ini memiliki panjang total hingga $200 \mathrm{~mm}$. Patagium (sayap) berupa perpanjangan enam pasang tulang rusuk yang diliputi kulit. Bunglon (Bronchocela jubata)saat penelitianditemukan berada di dahan pohon, berwarna hijau dengan ukuran sedang. Reptil ini dijumpai di plot 6 pada hari ke-11ditemukan 1 ekor selama penelitian.Bunglon yang berukuran sedang, berekor panjang menjuntai, panjang total hingga $550 \mathrm{~mm}$, dan empat-perlimanya adalah ekor, gerigi di tengkuk dan punggungnya lebih menyerupai surai.

Cicak kayu(Hemidactylus frenatus) ditemukan sering kali berada pada dahan pohon dan bebatuan, reptil ini ditemukan hampir setiap hari. Sisik-sisik berbentuk serupa bintik bulat halus di sisi dorsal (punggung), tidak seragam besarnya. Menurut Das (2010) ciri-ciri dari jenis ini adalah panjang tubuh maksimal $67 \mathrm{~mm}$ dengan bentuk tubuh kokoh dan agak memipih. Tokek (Gecko gecko) selama penelitian ditemukan sering kali berada pada dahan pohon dan bebatuan. Reptil ini ditemukan hampir disetiap hari saat penelitian dan plot. Cecak yang berukuran sedang hingga besar. Kulit punggung tertutupi oleh sisik-sisik granular, 
bercampur dengan bintil-bintil yang agak besar. Berikut disajikan hasil persentase pada Gambar 1 keanekaragam jenis reptil dalam diagram lingkaran.

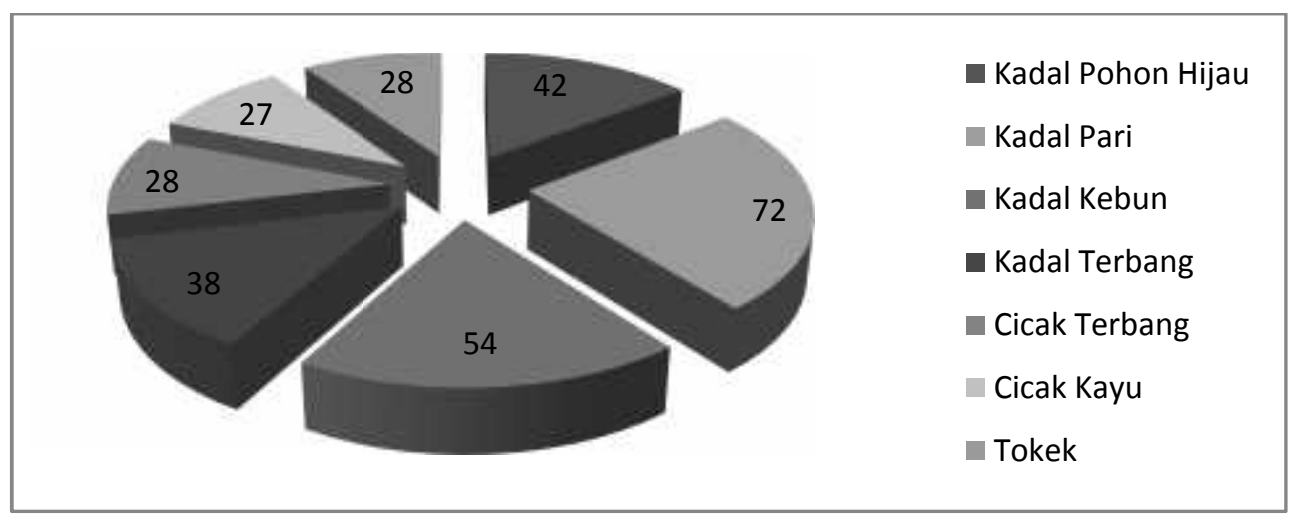

Gambar 1. Persentase Keanekaragaman Reptil diDesa Pekon Pahmungan Kecamatan

Pesisir Tengah Kabupaten Pesisir Barat (Plot Permanen Universitas Lampung), Juni 2015.

Keanekaragaman spesies dapat digunakan untuk mengukur stabilitas komunitas, yaitu suatu kemampuan komunitas untuk menjaga dirinya tetap stabil meskipun terdapat gangguan terhadap komponen-komponennya di mana suatu komunitas akan memiliki keanekaragaman spesies yang tinggi jika tersusun oleh banyak spesies (Soegianto, 1994; Indriyanto, 2006). Berdasarkan perhitungan indeks keanekaragaman pada setiap harinya diperoleh data keseluruhan yaitu 2,001 yang menunjukkan bahwa plot permanen Universitas Lampung memiliki tingkat keanekaragaman jenis masih cukup baik.

Struktur vegetasi hutan merupakan salah satu bentuk pelindung, yang digunakan oleh jenis-jenis reptil untuk tempat penyesuaian terhadap perubahan suhu (thermal cover), sehingga hilangnya vegetasi menyebabkan juga hilangnya sumber pakan dan tempat berlindung bagi reptil, menyatakan bahwa kuantitas dan kualitas pakan dapat mempengaruhi kesejahteraan satwa, sehingga kekurangan pakan dapat menyebabkan satwa berpindah (migrasi), terutama satwa ektotermal seperti reptil yang pergerakannya sangat dipengaruhi oleh suhu. Rapatnya vegetasi pada habitat berhutan vegetasi akan mempengaruhi intensitas sinar matahari yang masuk dan sampai ke lantai hutan (Alikodra 2002). Berikut Persentase keanekaragam jenis reptil di Repong Damar Pekon Pahmungan.

Faktor lain yang mempengaruhi keanekaragaman jenis reptil di repong damar pada umunya jarang sekali dibersihkan sehingga ditumbuhi semak, yang kemudian menjadi habitat bagi pakan reptil yaitu serangga, reptil kecil, amfibi, mamalia kecil, dan lain lain. Cuaca merupakan salah satu faktor yang mempengaruhi keberadaan reptil karena pada hari hujan reptil tidak mendapatkan intesitas cahaya matahari yang cukup untuk membatu metoblismenya. Menurut (Mattison, 2005) reptil sangat memerlukan suhu yang cukup untuk proses metabolismenya. Terbukti pada saat penelitian reptil sulit diketemukan pada saat hujan, diduga reptil memilih untuk bersembunyi sehingga lebih sulit untuk ditemukan.

\section{B. Indeks Kemerataan}

Nilai indeks kemerataan spesies dapat menggambarkan kestabilan suatu komunitas, yaitu bila angka nilai kesamarataan diatas 0,75 maka dikatakan komunitas stabil, bila angka kesamarataan berkisar antara 0,5 sampai 0,75 maka dikatakan labil, dan bila angka kesamarataan di bawah 0,5 maka dikatakan tertekan. Pernyataan tersebut sama halnya menyatakan bahwa semakin kecil nilai indeks kemerataan spesies maka penyebaran spesies pada suatu habitat semakin tidak merata.Nilai indeks kemerataan reptil di Desa Pekon 
Pahmungan Kecamatan Pesisir Tengah Kabupaten Pesisir Barat (Plot Permanen Universitas Lampung), seluruhnya memiliki nilai kemerataan diatas 0,927.Komunitas ini dapat dikatakan berada dalam kondisi yang stabilkarena memiliki nilai kemerataan adalah $0,75<J \leq 1$, dengan kata lain meratanya penyebaran komunitas reptil yang ditemukan di lokasi pengamatan, disajikan pada Gambar 2.

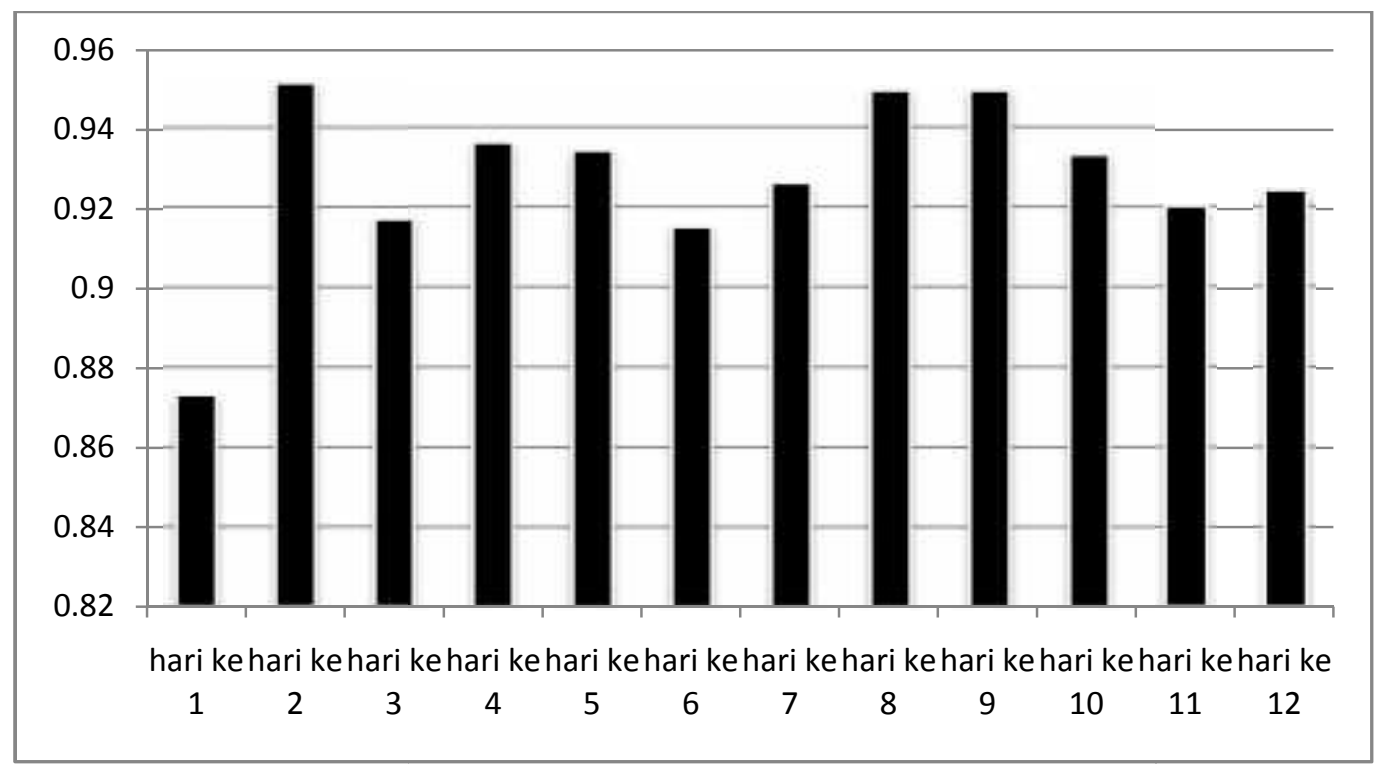

Gambar 2. Histogram indeks kesamarataan (J') reptil perhari diPekon Pahmungan Kecamatan Pesisir Tengah Kabupaten Pesisir Barat (Plot Permanen Universitas Lampung), Juni 2015

Kemerataan tinggi disebabkan oleh jumlah individu setiap jenis reptil yang dijumpai cukup merata dan hampir sama, yaitu rata-rata hanya dijumpai 3-5 individu. Apabila setiap jenis memiliki jumlah individu yang sama, maka komunitas tersebut mempunyai nilai kemerataan yang maksimum (Yusuf, 2008). Dominasi kadal pari dan kadal kebun di habitat tanah terbuka cukup banyak, kadal kebun memiliki kemampuan adaptasi yang lebih baik daripada jenis reptil lainnya, ditunjukan dengan jenis pakannya yang beragam bahkan memakan sisa-sisa makanan manusia. Hal ini diduga karena adanya keterkaitan dengan keberadaan rumah ladang dan aktifitas manusia yang menyisakan makanan yang kemudian dimanfaatkan oleh kadal kebun (Yusuf, 2008). Menurut Cox, Dijk, Nabhitabhata dan Thirakhupt(1998), kadal kebun ini merupakan jenis reptil yang memakan berbagai jenis invertebrata dan dapat berasosiasi disekitar tempat tinggal manusia. Seperti fauna pada umumnya, reptil bergantung pada mahluk hidup lainnya sebagai sumber makanan (Goin dan Goin 1971).

\section{Vegetasi dan Fungsi Habitat Bagi Reptil}

Kondisi wilayah di Pekon Pahmungan Kecamatan Pesisir Tengah Kabupaten Pesisir Barat (Plot Permanen Universitas Lampung) merupakan hutan rakyat, Kondisi tofografi Pekon Pahmungan adalah dataran tinggi, dengan ketinggian tanah dari permukaan laut dengan rata-rata $1000-1500 \mathrm{~m}$ dengan suhu maksimum rata-rata berkisar $28,6^{\circ} \mathrm{C}$ dan suhu minimum berkisar $22,7^{\circ} \mathrm{C}$. Lokasi penelitian tepatnya terletak di plot permanen Universitas Lampung yang berada di pekon pahmungan yang di dalamnya terdapat hutan rakyat yang didominasi pohon damar mata kucing, adapun tanaman lain seperti pada Tabel 2 dan tumbuhan bawah 
seperti semak-semak dan ilalang yang cukup rapat sehingga memberikan perlinduangan, berkembang biak, bermain, dan mencari makan bagi satwa liar.

Tabel 2. Jenis vegetasi di Desa Pekon Pahmungan Kecamatan Pesisir Tengah Kabupaten Pesisir Barat (Plot Permanen Universitas Lampung).

\begin{tabular}{clll}
\hline No & Nama Nasional & Nama Ilmiah & Famili \\
\hline 1. & Damar & Shorea javanica & Dipterocarpaceae \\
2. & Duku & Lansium domesticum & Meliaceae \\
3. & Durian & Durio zibethinus & Bombacaceae \\
4. & Jengkol & Pithecellobium lobatum & Mimosaceae \\
5. & Petai & Parkia speciosa & Mimosaceae \\
6. & Manggis & Garcinia mangostana & Guttiferae \\
7. & Beringin & Ficus benjamina & Moraceae \\
8. & Cempedak & Artocarpus champeden & Moraceae \\
9. & Tupak & Bacacaurea dulcis & Euphorbiaceae \\
10. & Binjai & Mangifera caesia & Anacardiaceae \\
11. & Tangkil & Gnetum gnemon & Gnetaceae \\
\hline
\end{tabular}

Menurut Margareta, Rahayuningsih dan Abdullah (2012), keanekaragaman habitat akan pengaruh terhadap keanekaragaman jenis suatu hewan. Semakin beranekaragam struktur habitat maka semakin besar keanekaragaman jenis hewan, hal ini karena habitat menyediakan sumberdaya yang cukup, khususnya sebagai tempat untuk mencari makan, berlindung, dan berkembang biak. Jalur penelitian yang berbatasan dengan masyarakat sehingga merupakan daerah/habitat peralihan (ekoton). Daerah ekoton memberikan kemudahan pada satwaliar dalam memenuhi kebutuhan hidupnya, terutama makanan (Alikodra 2002). Pemilik kebun damar hanya datang satu kali dalam seminggu untuk mengambil getah, sehingga hal ini diduga tidak mengganggu keberadaan satwaliar.

Reptil adalah komponen penting dari jaring makanan disebagian besar ekosistem. Mereka mengisi peran penting baik sebagai predator dan spesies mangsa. Spesies herbivora juga bisa menjadi penyebar biji yang penting, terutama pada habitat pulau. Penghapusan spesies dari ekosistem yang drastis dapat mengubah populasi organisme lain, tetapi mereka yang memiliki peran yang sangat berpengaruh dalam suatu ekosistem dikenal sebagai spesies kunci. Predator puncak, seperti buaya, sering sebagai jenis kunci, meskipun mereka juga berkontribusi pada rantai makanan sebagai mangsa saat mereka masih muda. Beberapa spesies dianggap penting untuk cara mereka memodifikasi habitat mereka

\section{Pemanfaatan Reptil dan Ancaman Konservasinya}

Reptil merupakan salah satu bagian dari tingginya kekayaan hayati yang dimiliki Indonesia (Iskandar dan Erdelen 2006), yang bisa diambil manfaatnya. Menurut Gibbons, Scott, Ryan, Buhlmann, Tuberville, Metts, Greene, Mills, Leiden, Poppy dan Winne (2000), disebutkan manfaat yang bisa diambil dari reptil diantaranya untuk bahan makanan, obat-obatan tradisional, hewan peliharaan. Di berbagai tempat di Indonesia reptil digunakan sebagai pemberantas hama. Bagian yang diperdagangkan yaitu kulit (Yuwono 1998), daging dan reptil hidup sebagai peliharaan (Mardiastuti dan Soehartono 2003). Pengambilan langsung dari alam merupakan salah satu ancaman terhadap kelangsungan hidup reptil di Indonesia, terutama kura-kura yang sangat sensitif apabila diambil dari alam, karena kelompok kura-kura memiliki resiko kematian telur dan anakan yang tinggi dan memerlukan waktu yang lama untuk bisa berepropduksi (TRAFFIC Southeast Asia 2001). Di sekitar lokasi 
penelitian repong damar tidak dijumpai kegiatan pemanfaatan dan reptil yang dimanfaatkan secara langsung oleh penduduk sekitar hutan. Gangguan manusia secara langsung terhadap kelompok reptilia di Repong Damar saat ini jarang terjadi, tetapi secara tidak langsung dapat terjadi pada habitatnya. Makin meningkatnya aktivitas manusia dalam memanfaatkan sumber daya alam, mengakibatkan berubahnya komposisi organisme di dalam ekosistem, yang pada gilirannya menjadi ancaman bagi kehidupan jenis fauna. Pada umumnya hewan akan meninggalkan habitatnya yang telah berubah, bahkan dapat mati karena tidak dapat menemukan makanannya yang cocok (Margareta, 2010).

\section{KESIMPULAN}

Berdasarkan hasil penelitian di Pekon Pahmungan Repong Damar Kabupaten Pesisir Barat (Plot Permanen Universitas Lampung) pada bulan Juni 2015keanekaragaman ditemukan 15 spesies reptil dengan jumlah individu 323 yang berasal dari 7 famili dan diperoleh nilai indeks keanekaragaman $\mathrm{H}^{\prime}=2,001$ yang termasuk dalam kategori sedang dan indeks kesamarataan $\mathbf{J}^{\prime}=0,927$ yang termasuk dalam kategori stabil. Spesies reptil yang sering dijumpai adalah kadal pari (Tachydromus sexlineatus), kadal kebun (Eutropis multifasciata), kadal pohon hijau (Dasia olivacea), kadal terbang (Draco obscurus), cicak terbang (Draco volans), tokek (Gecko gecko)dancicak kayu (Hemidactylus frenatus) $(\mathrm{n}=72$, $54,42,38,28,28,27)$.

\section{DAFTAR PUSTAKA}

Alikodra, H.S. 2002. Pengelolaan Satwaliar Jilid II. Buku. Yayasan Penerbit Fakultas Kehutanan IPB. 89 p.

Amri,S., B. Nurdjali, dan S. Siahaan. 2015. Keanekaragaman jenis reptil ordo squamata dikawasan hutan lindung gunung semahung desa sebatih kecamatan sengah temilakabupaten landak. Jurnal Hutan Lestari 3 (1) : 30 - 34.

Bappenas. 1993. Biodiversity Action Plan for Indonesia. Buku.Ministry of development planning/ national development planning agency. Jakarta. $15 \mathrm{p}$.

Cox M, P. Dijk, J. Nabhitabhata, K. Thirakhupt. 1998. A Photographic guideto snakes and other reptiles of peninsular malaysia, singapore and thailand. london, sidney, singapore. Journal. New Holland Publishers Ltd.

Das, I. 2010. Reptiles of South-East Asia. Buku. New Holland Publishers. UK. 123 p.

Firdaus, A. B., A. Setiawan, E.L. Rustiati., 2014. keanekaragaman spesies burung di repong damar pekon pahmungan kecamatan pesisir tengah krui kabupaten lampung Barat. Jurnal Sylva Lestari.2(2): 1-6.

Gibbons, J., D. Scott, T. Ryan, K. Buhlmann, T. Tuberville, B. Metts, J. Greene, T. Mills, Y. Leiden, S. Poppy, T. Winne. 2000. The global decline of reptiles déjà vu amphibians. bioscienceJournal. (50) 8: 653-666.

Goin C.J., O.B. Goin. 1971. Introduction to herpetology. Buku. San Francisco: WH Freeman and Company. $154 \mathrm{p}$.

Heyer, W.R., M.A., Donnelly., McDiarmid., Hayek \& M.S., Foster. (eds). 1994. Measuring and monitoring biological diversity. standar methods for amphibians. Buku. Smithsonian Institution Press, Washington DC. 76 p.

Indriyanto. 2006. Ekologi Hutan. Buku. Bumi Aksara. Jakarta. 43 p.

Iskandar D. T. and Erdelen. 2006. Conservation of amphibians and reptiles in indonesian : issue and problems. Buku. Institut Teknologi Bandung. Bandung. 54 p.

Jasin. 1984, Sistematik hewan (invertebrata dan vertebrata). Buku. Sinar Jaya, Surabaya. 32p. 
Kusrini M.D, W., Endarwin., A.UI-Hasanah., M., Yazid. 2007. Metode pengamatan herpetofauna di taman nasional batimurung bulusaraung, sulawesi selatan. modul pelatihan. Jurnal.Departemen Konservasi Sumberdaya Hutan dan Ekowisata, Fakultas Kehutanan IPB, Bogor. 7-12

Mardiastuti A., T. Soehartono. 2003. Di dalam: Kusrini MD, Mardiastuti A, Fitri A, editor. Konservasi amfibi dan reptil di indonesia. Jurnal. Bogor: Indonesian Reptile and Amphibian Trade Association (IRATA).131-144

Margareta, Rahayuningsih, dan M. Abdullah. 2012. Persebaran dan keanekaragaman herpetofauna dalam mendukung konservasi keanekaragaman hayati di kampus sekaran universitas negeri semarang. IndonesianJournal of Conservation 1 (1) [ISSN: 2252-9195]Hlm. 1-10.

Mattison, C. 2005. encyclopedia of reptiles and amphibians. Buku.The Brown Reference Group plc. Singapore. 79 p.

Mistar. 2003. panduan lapangan amfibi kawasan ekosistem leuser.Buku.Perpustakaan Nasional. Jakarta. 67 p.

Nainggolan, V.,dan B. S. Dewi, 2011. Analisis populasi jenis primata di repong damar pekon pahmungan kecamatan pesisir tengan kabupaten lampung barat.Skripsi. Fakultas Pertanian,Universitas Lampung. Lampung. 56 p.

Soegianto, A. 1994. Ekologi kuantitatif: metode analisis populasi dan komunitas.Buku.Usaha Nasional. Jakarta. 32 p.

TRAFFIC Southeast Asia. 2001. An Overview of the trade in live south-east asian freshwater turtles. Journal AC17 Inf 71-5.

Tweedie, M.W.F. 1983. The snakes of malaya. Buku The Singapore National Printers. Singapore. $98 \mathrm{p}$.

World Wildlife Fund Indonesia, Kehutanan. 2007. Indonesia. http://www.wwf.or.id/ tentang_wwf/upaya_kami/forest_spesies/tentang_forest_spesieskehutanan/ diakses 11 agustus 2015.

Yusuf,2008. Studi keanekaragaman jenis reptil pada beberapa tipe habitat di eks-hph pt rki kabupaten bungo propinsi jambi.Skripsi. Departemen Konservasi Sumberdaya Hutan dan Ekowisata fakultas Kehutanan Institut Pertanian Bogor. p 5-40.

Yuwono F.B. 1998. Di dalam: Erdelen W, editor. Conservation Trade and Sustainable Use of Lizards and Snakes in Indonesia-Mertensiella. Jurnal. Germany: Reinbach.7:9-15. 
Vol. 4 №. I, Januari 20I6 (51-60)

Halaman ini sengaja dikosongkan 